\title{
Characterization of a novel protein that specifically binds to DNA modified by $\mathrm{N}$-acetoxy-acetylaminofluorene and cis-diamminedichloro- platinum
}

\author{
Monika Pietrowska and Piotr Widłak ${ }^{\bowtie}$ \\ Department of Experimental and Clinical Radiobiology, Maria Skłodowska-Curie Memorial Cancer Center and \\ Institute of Oncology, Gliwice, Poland; ${ }^{\circledR}$-mail: widlak@io.gliwice.pl
}

Received: 01 February, 2005; revised: 10 March, 2005; accepted: 16 May, 2005

available on-line 06 June, 2005

\begin{abstract}
Proteins recognizing DNA damaged by the chemical carcinogen $N$-acetoxy-acetylaminofluorene (AAAF) were analyzed in nuclear extracts from rat tissues, using a $36 \mathrm{bp}$ oligonucleotide as a substrate and electrophoretic mobility shift and Southwestern blot assays. One major damage-recognizing protein was detected, whose amount was estimated as at least $10^{5}$ copies per cell. Levels of this protein were similar in extracts from brain, kidney and liver, but much lower in extracts from testis. The affinity of the detected protein for DNA damaged by AAAF was about 70-fold higher than for undamaged DNA. DNA damaged by cis-diamminedichloroplatinum (cis-DDP), benzo(a)pyrene diolepoxide (BPDE) or UV-radiation also bound this protein with an increased affinity, the former more strongly and the latter two more weakly as compared to AAAF-damaged DNA. The detected AAAF/DDP-damaged-DNA-binding (AAAF/DDP-DDB) protein had a molecular mass of about $25 \mathrm{kDa}$ and was distinct from histone $\mathrm{H1}$ or HMGB proteins, which are known to have a high affinity for cis-DDP-damaged DNA. The level of this damage-recognizing protein was not affected in rats treated with the carcinogen 2-acetylaminofluorene. The activity of an AAAF/DDP-DDB protein could also be detected in extracts from mouse liver cells but not from the Hep2G human hepatocellular carcinoma.
\end{abstract}

Keywords: acetylaminofluorene, cisplatin, damaged DNA-binding protein, damage recognition

All organisms are under permanent pressure from genotoxic agents that damage DNA, and all of them have evolved mechanisms for recognition and repair of DNA damage. Nucleotide excision repair (NER) is an important and universal pathway that removes a broad spectrum of DNA damages. NER recognizes and repairs not only bulky lesions induced by UV-irradiation, polycyclic hydrocarbons or aromatic amines, but also oxidative base damages (reviewed in: Araujo \& Wood, 1999; Petit \& Sancar, 1999; de Laat et al., 1999). The first step of any repair mechanism is damage recognition. It is currently postulated that different protein complexes involved in NER may take part in damage recognition, depending on the type of damage and the NER sub-pathway. Among such complexes in eukaryotic cells are XPC/HR23B, UVDDB (XPE) and XPA/RPA. All of these posses a high affinity for UV-irradiated DNA, yet this pref- erence is different for each of them (reviewed in Wood, 1999). Many other proteins that preferentially bind DNA lesions repaired by NER have been detected in different organisms, but their relevance to DNA repair has not been established (Protic \& Levine, 1993; Protic, 1994). Among these damaged DNA-binding (DDB) proteins is the chromatin protein HMGB1 (formerly termed HMG-1) (and other HMG-box containing proteins), which was found to have a high affinity for DNA damaged by cis-diamminedichloroplatinum (cis-DDP) (Pil \& Lippard, 1992), chromium (Wang et al., 1997), UV radiation (Pasheva et al., 1998) and benzo(a)pyrene diolepoxide (BPDE) (Łanuszewska \& Widłak, 2000). It has been proposed that HMG-box containing proteins may compete with DNA repair proteins, making repair less efficient and facilitating apoptosis induced by cis-DDP (Chu, 1994). On the other hand, it has been more recently reported that another HMG

Abbreviations: AAAF, N-acetoxy-acetylaminofluorene; BPDE, benzo(a)pyrene diolepoxide; cis-DDP, cis-diamminedichloroplatinum; DDB, damaged DNA-binding (protein); HMG, high mobility group (protein); NER, nucleotide excision repair; 2-AFF, 2-acetylaminofluorene. 
protein - HMGN1 - enhances the rate of repair of UV-damaged chromatin substrates (Birger et al., 2003). Another known chromatin protein that preferentially binds to cis-DDP-damaged DNA is histone H1 (Yaneva et al., 1997).

The aromatic amine 2-aminofluorene (2-AF) and its acetylated derivative 2-acetylaminofluorene (2-AAF) are known hepatocarcinogens. The formation of covalent DNA adducts seems to be an essential step in carcinogenesis induced by these compounds (Kroese et al., 1988; Poirier et al., 1991). After their metabolic activation, 2-AAF derivatives form a mixture of non-acetylated and acetylated adducts, mostly at guanine residues; dG-C8-AF, dG-C8-AAF and $\mathrm{dG}-\mathrm{N}^{2}-\mathrm{AAF}$ are the major forms (reviewed in Heflich \& Neft, 1994). The DNA adducts induced by 2-AAF and its derivatives are repaired by NER pathways. However, some aspects of their repair differ from that of other bulky DNA adducts, e.g. those induced by benzo(a)pyrene or UV radiation. In contrast to UV-induced photoproducts, adducts induced by $N$-acetoxy-acetylaminofluorene (AAAF) were not preferentially removed from the transcriptionally active dihydrofolate reductase gene in Chinese hamster ovary cells (Tang et al., 1989), and their removal from the hypoxanthine phosphoribosyltransferase gene in human fibroblasts was significantly slower than that of adducts induced by benzo(a)pyrene diolepoxide (BPDE), and was not biased toward the transcribed strand (McGregor et al., 1997). While DNA lesions induced by either UV radiation or benzo(a)pyrene were preferentially repaired in nuclear matrix-bound DNA, adducts induced by 2-AAF derivatives were not preferentially removed from matrix-attached DNA (Widłak \& Rzeszowska-Wolny, 1999). The reasons for the less efficient repair of AAF-induced adducts than of other bulky DNA lesions are not clear at the moment; however, the mechanisms of damage recognition may contribute to these differences.

Proteins that specifically recognize DNA damage induced by 2-AAF derivatives are poorly understood in comparison to proteins recognizing UV-irradiated or cis-DDP-damaged DNA. In fact, no such proteins has been purified to homogeneity and identified, neither its relevance to DNA repair established. We have previously shown that HMGB1/2 proteins have a somehow elevated affinity for DNA damaged by AAAF (Łanuszewska \& Widłak, 2000). Two additional proteins that specifically bind DNA damaged by AAAF have also been detected in nuclear extracts from rat liver cells (Rzeszowska-Wolny \& Widlak, 1999). We have shown that one such AAAF-DDB protein had an apparent molecular size of $42 \mathrm{kDa}$ and a relatively weak affinity for AAAFdamaged DNA (about 8-fold higher compared to non-damaged DNA) (Pietrowska et al., 2000). Here we aimed to identify and characterize a second AAAF-DDB protein from rat liver and to evaluate its role in DNA repair. We found that this abundant protein bound also with a high affinity DNA damaged by cis-DDP but not DNA which had been UV-irradiated or damaged by BPDE, and termed it AAAF/DDP-DDB.

\section{MATERIALS AND METHODS}

DNA substrates. A synthetic double-stranded 36 bp-long oligonucleotide (5'-AATTCGTAGG CCTAAGAGCA ATCGCACCTG TGCGCG-3', with blunt ends) was used as a model DNA substrate. The oligonucleotide (at $10 \mu \mathrm{M}$ concentration) was incubated for $4 \mathrm{~h}$ at $37^{\circ} \mathrm{C}$ with $40 \mu \mathrm{M}$ AAAF or BPDE (Midwest Research Institute, USA), or for $20 \mathrm{~h}$ at $37^{\circ} \mathrm{C}$ with $3 \mu \mathrm{M}$ cis-DDP (Ebewe), and then purified by phenol/chloroform extraction and ethanol precipitation. Alternatively, the oligonucleotide was UVirradiated $\left(5 \mathrm{~kJ} / \mathrm{m}^{2}\right)$ using a $254 \mathrm{~nm}$ UV-crosslinker (Stratagene). The treatment with AAAF, BPDE and $\mathrm{UV}$ introduced on average a single lesion into about $15 \%$ of the DNA molecules, which was verified by a ${ }^{32}$ P-postlabeling method (Rzeszowska-Wolny \& Widlak, 1999). According to the literature (Ushay et al., 1981), the treatment with cis-DDP should introduce a similar degree of damage. The oligonucleotide was end-labeled by transfer of ${ }^{32} \mathrm{P}$ from $\left[\gamma^{32} \mathrm{P}\right] \mathrm{ATP}$ using T4 polynucleotide kinase and purified from $6 \%$ polyacrylamide gels as described elsewhere (Rzeszowska-Wolny \& Widlak, 1999).

Preparation of nuclear extracts. Nuclei were purified from homogenized tissues of adult male WAG rats. To obtain extracts of nuclear proteins, nuclei were incubated for $30 \mathrm{~min}$ at $4^{\circ} \mathrm{C}$ with a buffer consisting of $10 \mathrm{mM}$ Hepes/NaOH pH 7.9, $1.5 \mathrm{mM}$ $\mathrm{MgCl}_{2}, 0.1 \mathrm{mM}$ EGTA, $0.5 \mathrm{mM}$ dithiothreitol (DTT), $5 \%$ glycerol, a protease inhibitor mixture (Comple$\mathrm{te}^{\mathrm{TM}}$, Boehringer), and $\mathrm{NaCl}$ at different molarities ranging from 0.1 to $2.0 \mathrm{M}$. Nuclei extracted at a salt concentration higher than $0.5 \mathrm{M}$ were briefly (2-3 s) sonicated. Insoluble remnants of the nuclei were pelleted by centrifugation for $30 \mathrm{~min}$ at 16000 r.p.m. at $4^{\circ} \mathrm{C}$. Alternatively, nuclear extracts were prepared from mouse liver cells or Hep2G human hepatocellular carcinoma cells. Protein concentration was assayed with the Protein Assay Kit (BioRad). Proteins were resolved on $13 \%$ polyacrylamide/SDS gels and stained with silver or Coomassie Brilliant Blue.

Preparation of histone $\mathrm{H} 1$ and HMG proteins. Histone $\mathrm{H} 1$ was purified from rat liver nuclear extracts according to a modified method of Banchev et al. (1991) using CM-Sephadex chromatography. Briefly, nuclear proteins extracted with 0.5 $\mathrm{M} \mathrm{NaCl}$ were loaded onto a CM-Sephadex C-25 column equilibrated with $0.5 \mathrm{M} \mathrm{NaCl}$ and $10 \mathrm{mM}$ sodium phosphate buffer ( $\mathrm{pH}$ 7.0). Non-histone proteins were eluted from the column with $0.5 \mathrm{M} \mathrm{NaCl}$, then 
the histone H1-containing fraction was eluted with $0.7 \mathrm{M} \mathrm{NaCl}$. Alternatively, histone $\mathrm{H} 1$ was purified from rat liver chromatin using hydroxyapatite chromatography according to Stein (1989). HMG proteins were purified from rat liver nuclei according to Spiker (1984). Briefly, proteins extracted with $0.4 \mathrm{M}$ $\mathrm{NaCl}$ were precipitated with $2 \%$ trichloroacetic acid and the acid-soluble fraction containing HMG proteins was concentrated by precipitation with acetone. Alternatively, a mixture of HMGB1 and HMGB2 proteins purified from calf thymus was purchased from Waco Chemicals.

Electrophoretic mobility shift assay (EMSA). Radioactive oligonucleotide (25 ng) was incubated with nuclear proteins $(5 \mu \mathrm{g})$ for $30 \mathrm{~min}$ at $4^{\circ} \mathrm{C}$. The binding buffer consisted of $20 \mathrm{mM}$ Tris/ $\mathrm{HCl}, \mathrm{pH}$ 7.6, $5 \mathrm{mM} \mathrm{MgCl}_{2}, 0.5 \mathrm{mM}$ EDTA, $1 \mathrm{mM}$ DTT, 5\% glycerol and $\mathrm{NaCl}$ (150 mM final concentration). Protein-oligonucleotide complexes were formed in a final volume of $20 \mu \mathrm{l}$ in the presence of non-radioactive DNA competitors added before the proteins. Sonicated Escherichia coli DNA was used as a non-specific competitor at an 80-fold excess (2 $\mu \mathrm{g})$. Either undamaged or damaged oligonucleotide was used as a homologous competitor. Protein-oligonucleotide complexes were resolved by electrophoresis on $6 \%$ polyacrylamide gel in $0.5 \times$ Tris/borate/EDTA buffer. Gels were dried, marked with radioactive ink, and autoradiographed. Gel fragments containing radioactive complexes were excised and quantified by scintillation counting.

Southwestern blot analysis. Nuclear proteins $(50 \mu \mathrm{g}$ of nuclear extracts or $5 \mu \mathrm{g}$ of histone

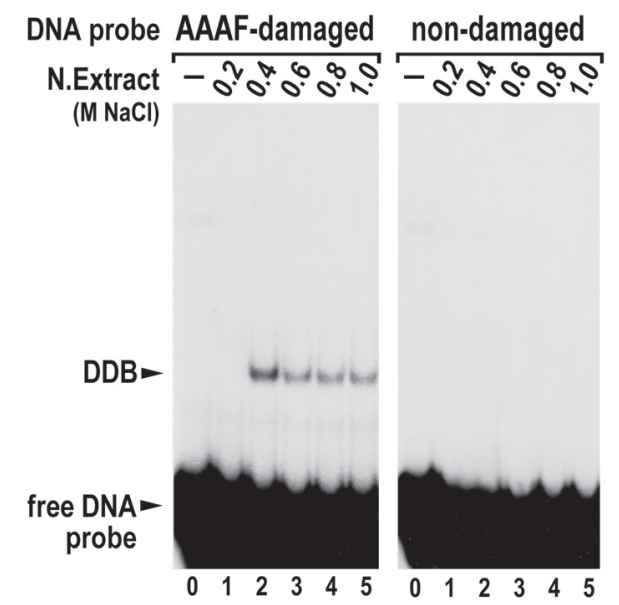

Figure 1. Detection of proteins recognizing AAAF-damaged oligonucleotide by EMSA.

Labeled oligonucleotide (either AAAF-damaged or undamaged) was incubated with proteins extracted from rat liver nuclei with buffers of increasing $\mathrm{NaCl}$ concentration from 0.2 to $1.0 \mathrm{M}$, in the presence of excess non-radioactive competitor (E. coli DNA). Lanes 0 contain the oligonucleotide alone. Arrowheads denote the positions of the free oligonucleotide and the complex containing DDB proteins.
H1 and HMG preparations) were fractionated on $13 \%$ polyacrylamide/SDS gels and electrotransferred onto PVDF membranes (Hybond-P, Amersham) in $25 \mathrm{mM}$ Tris, $190 \mathrm{mM}$ glycine and 20\% methanol. Filter-bound proteins were renatured by incubation in a hybridization oven for $5 \mathrm{~h}$ at $25^{\circ} \mathrm{C}$ with $25 \mathrm{mM}$ Tris/ $\mathrm{HCl} \mathrm{pH}$ 7.6, $100 \mathrm{mM} \mathrm{NaCl}, 1 \mathrm{mM}$ EDTA, $1 \mathrm{mM}$ DTT, $5 \mathrm{mM} \mathrm{MgCl}_{2}$ and $2.5 \%$ bovine serum albumin (BSA). After washing with binding buffer (same composition as above but with $0.25 \%$ BSA) the filters were incubated for $5 \mathrm{~h}$ at $25^{\circ} \mathrm{C}$ in binding buffer supplemented with $250 \mathrm{ng}$ of ${ }^{32} \mathrm{P}$-end-labeled oligonucleotide and an 80-fold excess of non-radioactive competitor (E. coli DNA) in a final volume of $10 \mathrm{ml}$. Filters were then washed with the binding buffer and autoradiographed.

Assay of DNA adducts. Rats were injected intraperitoneally with 2-AAF $(50 \mathrm{mg} / \mathrm{kg}$ of body weight, dissolved in DMSO) and tissue samples were collected at different times after the injection. DNA isolated from the tissues, as well as the oligonucleotide used for EMSA, were assayed for the presence of adducts by ${ }^{32} \mathrm{P}$-postlabeling (Gupta, 1985). DNA adducts were extracted by butanol extraction and ${ }^{32} \mathrm{P}$-labeled nucleotides were resolved by multi-dimensional thin-layer chromatography. Adduct spots were visualized by autoradiography, cut out from TLC plates, and quantified by scintillation counting.

\section{RESULTS AND DISCUSSION}

One major complex binding a $36 \mathrm{bp}$ oligonucleotide damaged by $\mathrm{N}$-acetoxy-acetylaminonofluorene is detected in nuclear extracts

Nuclear extracts from rat liver cells were analyzed for the presence of proteins binding to AAAFdamaged DNA (AAAF-DDB proteins) using the electrophoretic mobility-shift assay. In this method, proteins having an affinity for a radio-labeled damaged DNA (chosen not to contain any established consensus sequence for transcription factor binding sites) are detected by gel electrophoresis in the form of a retarded band containing a protein-DNA complex (Protic \& Levine, 1993). Figure 1 shows the results of an experiment in which proteins extracted from isolated nuclei with increasing concentrations of $\mathrm{NaCl}$ (from 0.2 to $1.0 \mathrm{M}$ ) were incubated with radioactive oligonucleotide, either damaged by AAAF or undamaged, in the presence of a non-specific competitor (E. coli DNA). Complexes that specifically recognized AAAF-damaged DNA were detected when fractions extracted from nuclei with $0.4 \mathrm{M}$ and higher concentrations of $\mathrm{NaCl}$ were tested, suggesting that proteins responsible for formation of such complexes are strongly attached to chromatin. The proportion of such proteins to total extracted pro- 
teins was the highest in $0.4 \mathrm{M} \mathrm{NaCl}$ extracts. Formation of the complex was optimal in $0.2-0.4 \mathrm{M} \mathrm{NaCl}$ and persisted up to $0.8 \mathrm{M} \mathrm{NaCl}$, and was ATP- and magnesium-independent (not shown). The complex had an electrophoretic mobility similar to that of a $100 \mathrm{bp}$-long double stranded DNA. When an excess of an other frequently used competitor, poly $\mathrm{dI}-\mathrm{dC}$ alternating copolymer, was used, an additional minor AAAF-DDB complex could also be detected (not shown; Pietrowska et al., 2000).

The major AAAF-DDB protein also recognizes other bulky DNA damage

To detect proteins that recognize other DNA lesions, the oligonucleotide damaged by different agents was used as a substrate. Figure 2 shows that the majority of DNA damaged by cis-DDP formed two complexes (lane 4), while UV-irradiated DNA formed a further different complex (lane 5). To examine the binding of proteins in the major AAAFDDB complex to DNA damaged by other agents, labeled oligonucleotide damaged by AAAF was incubated with proteins in the presence of an excess of the same oligonucleotide either undamaged or damaged as a homologous competitor. The results in Fig. 2 (middle panel) show that the proteins present in this complex have a strong affinity also for DNA damaged by cis-DDP (lane 10) and a weaker affinity for DNA damaged by BPDE or by UV radiation (lanes 8 and 9), although still stronger than for undamaged DNA (lane 6). DNA methylated by DMS did not have an enhanced affinity for those proteins (not shown). Other experiments with homologous competitors showed that one of the proteins binding DNA damaged by cis-DDP (that in the complex with the higher mobility) recognized the oligonucleotide damaged by AAAF (Fig. 2, right panel, lane 13). We propose that the same protein formed the major complex with AAAF-damaged DNA and recognized DNA damaged by cis-DDP. Hereafter this protein is termed AAAF/DDP-DDB.

To estimate the affinity of the AAAF/DDPDDB protein for oligonucleotide damaged by different agents, complexes between the extracted proteins and labeled AAAF-damaged oligonucleotide were formed in the presence of homologous competitors in amounts increasing two-fold from 0.031 to $2 \mu \mathrm{g}$ (not shown). The affinity for AAAF-damaged oligonucleotide of the protein in the major complex was at least 64-fold greater than that for undamaged DNA (i.e., $0.031 \mu \mathrm{g}$ of AAAF-damaged oligonucleotide was as good a competitor as $2 \mu \mathrm{g}$ of undamaged one). The protein in this complex bound to oligonucleotide damaged by cis-DDP with an affinity about 8-fold higher than that for AAAF-damaged oligonucleotide, while its affinity for oligonucleotide damaged by BPDE or UV was about 8-fold lower as compared to the AAAF-damaged one (not shown). When DNA damaged by AAAF was thermally denatured before the binding reaction its efficiency as a competitor decreased 4-fold, suggesting that the proteins in the complex have a lower affinity for single stranded than for double stranded DNA. An experiment in which supercoiled pUC19 plasmid DNA damaged by AAAF, either intact or linearized by EcoRI restriction enzyme, was used as a competitor showed that the proteins in the complex have a slightly higher affinity (approx. 2-fold) for supercoiled than for linear DNA (not shown).

The major protein detected in rat liver that recognizes DNA damaged by AAAF is very abundant one. Assuming that each protein molecule binds a single molecule of damaged oligonucleotide and that the protein is completely extracted with 0.6 $\mathrm{M} \mathrm{NaCl}$, and based on the amount of DNA bound when present in excess, we calculated that a single cell may contain about $7 \times 10^{5}$ copies of the AAAF/ DDP-DDB protein.

Exposure of rats to 2-AAF does not affect the level of AAAF-DDB proteins

Some factors that damage DNA increase the level of damage-recognizing proteins, e.g. UV-DDB protein (Vaisman \& Chaney, 1995). Here we aimed

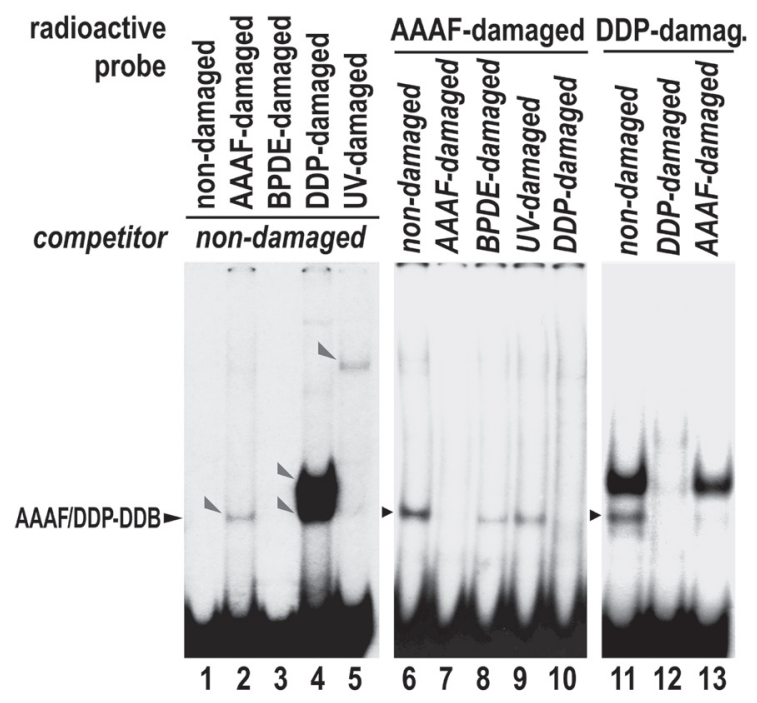

Figure 2. Analysis of substrate specificity of DNA damage recognition proteins from rat liver.

Labeled oligonucleotide (either non-damaged or damaged with different agents) was incubated with $0.4 \mathrm{M} \mathrm{NaCl}$ nuclear extracts, in the presence of a 50-fold excess of nondamaged oligonucleotide as a specific competitor (left). Complexes between nuclear proteins and labeled oligonucleotide damaged by AAAF (middle) or cis-DDP (right) were formed in the presence of non-damaged or damaged oligonucleotide as a homologous competitor. Complexes containing DDB-proteins are marked with slanted arrowheads, the position of the AAAF/DDP-DDB complex is denoted with a horizontal arrowhead. 
to examine whether treatment of animals with 2AAF affected the level of AAAF/DDP-DDB proteins. Rats were injected with the carcinogen and the levels of DNA adducts and of DDB complexes were compared in the liver at different times after the treatment. Treatment with 2-AAF induced DNA adducts, which reached the peak about $48 \mathrm{~h}$ after injection (Fig. 3A and 3C). The level of the AAAF-DDB complex was not affected at any time after the treatment with 2-AAF (Fig. 3B and 3C). We also did not observe any correlation between the levels of DNA damage and of AAAF/DDP-DDB proteins in individual animals. Treatment of rats with another chemical carcinogen, benzo(a)pyrene, also did not affect the

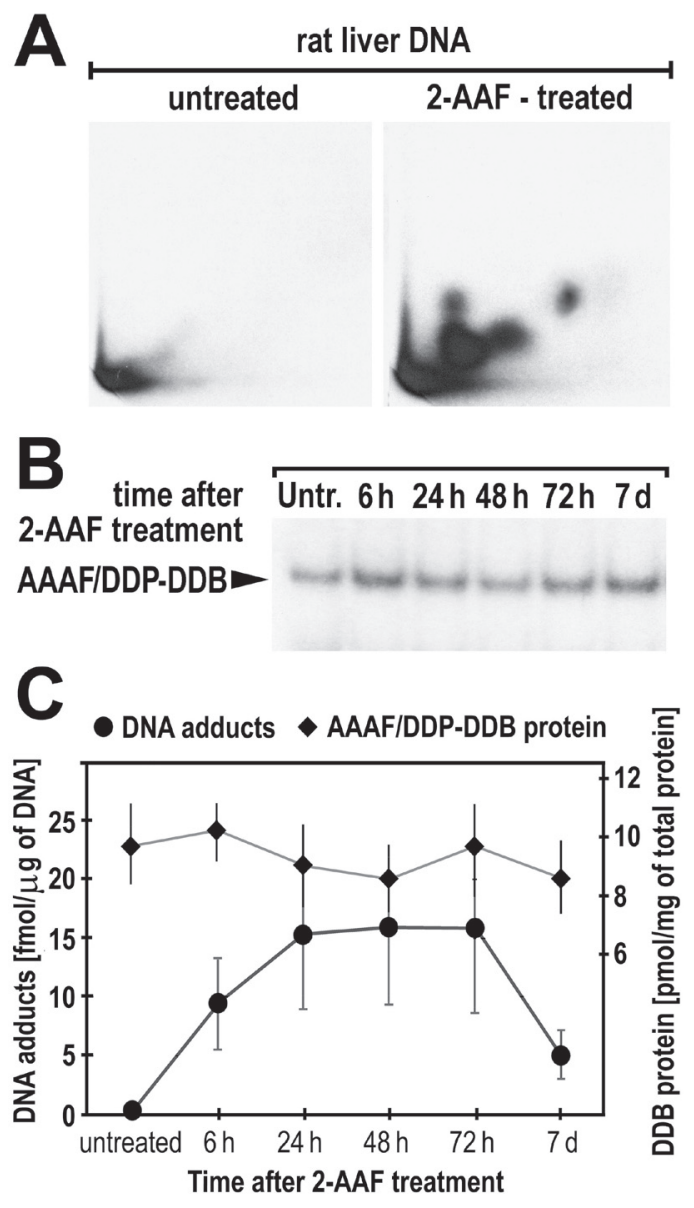

Figure 3. Level of AAAF/DDP-DDB protein is not affected by treatment of animals with 2-AAF.

Panel A. Thin-layer chromatograms of DNA adducts from livers of untreated and 2-AAF-treated rats $(48 \mathrm{~h}$ after injection) analyzed by ${ }^{32}$ P-postlabeling. Panel B. Analysis of the AAAF/DDP-DDB protein in animals injected with 2AAF. Nuclear extracts were purified from livers of either untreated or 2-AAF-treated rats at different periods after the treatment and analyzed by EMSA. Panel C. Comparison of the levels of DNA adducts and of the AAAF/DDPDDB protein in livers of rats treated with 2-AAF. Values are means for 3 animals $( \pm$ S.D.). The amounts of the AAAF/DDP-DDB protein ( $\mathrm{pmol} / \mathrm{mg}$ of extracted proteins) were calculated based on the radioactivity of the bound DNA probe assuming that each protein molecule binds a single molecule of the DNA probe.

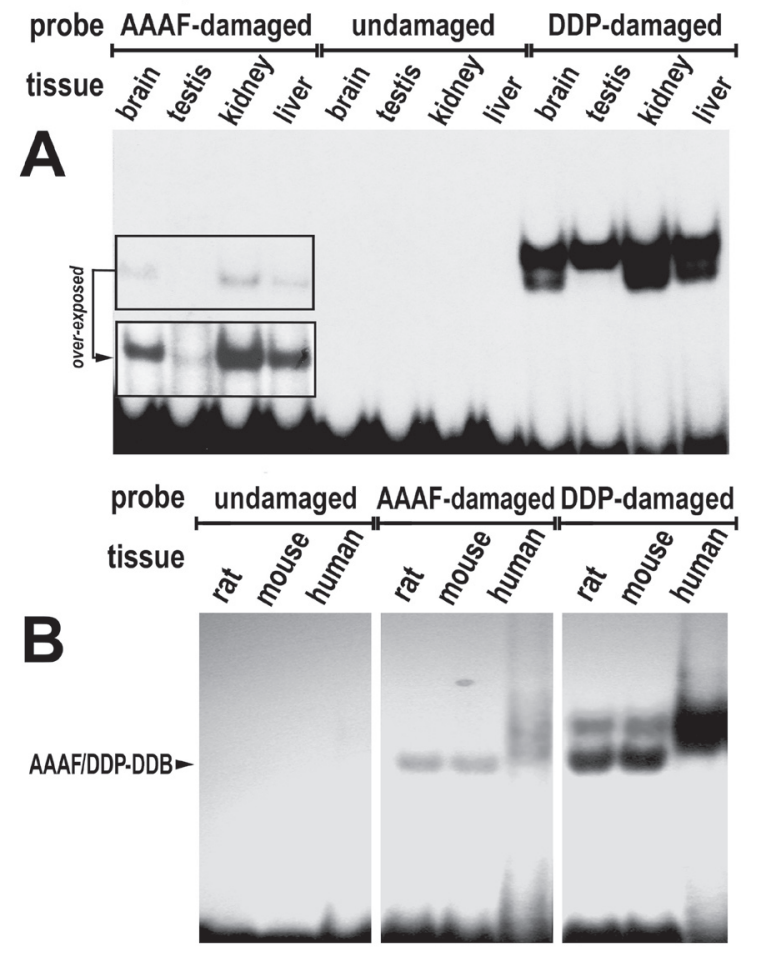

Figure 4. Detection of DNA damage recognizing proteins in different tissues.

Proteins extracted with $0.4 \mathrm{M} \mathrm{NaCl}$ from nuclei purified from rat tissues were incubated with labeled oligonucleotide, either undamaged or damaged by AAAF or cisDDP (panel A). Alternatively, labeled oligonucleotides were incubated with nuclear proteins extracted from rat and mouse liver cells or human hepatocellular carcinoma cells (panel B). The inset in panel A represents fragment of an over-exposed film.

levels of AAAF/DDP-DDB proteins at 24 and $48 \mathrm{~h}$ after treatment (not shown). In contrast, treatment with 2-AAF increased the level of UV-DDB protein in the extracts with a maximal effect observed $48 \mathrm{~h}$ after treatment (not shown).

Proteins recognizing DNA damaged by AAAF are detected in different rat tissues

To examine whether the AAAF/DDP-DDB proteins are common to different types of cells, their presence was studied in nuclear extracts from different rat tissues (Fig. 4A). Extracts from different tissues were complexed with the oligonucleotide damaged by either AAAF or cis-DDP. The level the AAAF/DDP-DDB protein was similar in three tissues tested (about 10, 11 and 9 pmol per mg of total extracted proteins in brain, kidney and liver, respectively). This level was much lower in extracts from testis ( $2 \mathrm{pmol} / \mathrm{mg}$ ), and similar observation was made when radioactive oligonucleotide damaged by cis-DDP was tested: testis contained much less protein forming the higher mobility complex (AAAF/ DDP-DDB), while the level of the DDP-DDB protein 
forming the lower mobility complex was similar in all four tissues. The activity of an AAAF/DDP-DDB protein could not be detected in extracts from white blood cells of rats (data not shown). Treatment of rats with 2-AAF or benzo(a)pyrene did not affect the level of the AAAF/DDP-DDB protein in any of the tissues tested (not shown).

To study the species-specificity of the expression of the AAAF/DDP-DDB protein, its activity was analyzed in nuclear extracts from mouse liver cells and Hep2G human hepatocellular carcinoma cells. The activity of the AAAF/DDP-DDB protein was similar in extracts from rat and mouse hepatocytes. However, although proteins that formed complexes with DNA damaged by AAAF or cis-DDP could be detected in extracts from Hep2G cells, the electrophoretic mobility of such complexes was apparently lower than observed for those specific for mouse and rat AAAF/DDP-DDB protein (Fig. 4B).

The major protein recognizing DNA damaged by AAAF is neither HMGB nor histone $\mathrm{H1}$

It has been shown that HMGB1/2 proteins (Pil \& Lippard, 1992) and histone H1 (Yaneva et al., 1997) are the major proteins recognizing DNA damaged by cis-DDP. In aim to identify a protein present in the AAAF/DDP-DDB complex we first check whether such complex is formed by either histone $\mathrm{H} 1$ or HMGB proteins. Histone $\mathrm{H} 1$ and HMG proteins were isolated from rat liver nuclei (Fig. 5A, lane 1 and 4). Figure 5B shows the results of an experiment in which preparations of histone $\mathrm{H} 1, \mathrm{HMG}$ proteins and nuclear extracts (either 0.2 or $0.4 \mathrm{M}$
$\mathrm{NaCl}$ ) were incubated with labeled oligonucleotide damaged by AAAF or cis-DDP, and the complexes formed were analyzed by EMSA. The lower mobility complex specific for DNA damaged by cis-DDP was detected in both types of nuclear extracts and HMG preparation but not in histone H1 preparation. As one could expect, this complex contained HMGB1/2 protein, which was verified by super-shift experiments with anti-HMGB1 antibody (not shown) and Southwestern-blotting (described below). The higher mobility complex specific for DNA damaged by cis-DDP or AAAF was detected only when the $0.4 \mathrm{M} \mathrm{NaCl}$ nuclear extract was tested (Fig. 5B, lanes $3)$. This shows that AAAF/DDP-DDB protein is neither a histone $\mathrm{H} 1$ variant nor $\mathrm{HMGB} 1 / 2$ protein. In consistency with this notion, the AAAF/DDP-DDB protein could be recovered from $2 \%$ trichloroacetic acid (TCA) precipitates of $0.4 \mathrm{M} \mathrm{NaCl}$ extracts (not shown).

Another in vitro method that can be used as a supplementary analytical tool to study DDB-proteins is Southwestern blotting, in which a DNA probe binds to membrane-bound proteins after their electrophoretic resolution (Protic \& Levine, 1993). As proteins are usually resolved on SDS-containing gels, this assay depends on the ability of the tested proteins to recover their native structure upon removal of SDS. Figure 5C shows the results of an experiment in which electrophoretically resolved proteins from nuclear extracts (either 0.2 or $0.4 \mathrm{M} \mathrm{NaCl}$ ), histone $\mathrm{H} 1$ and $\mathrm{HMG}$ preparations were probed with labeled oligonucleotide either undamaged or damaged by AAAF or cis-DDP. Histone $\mathrm{H} 1$ bound both undamaged and damaged DNA (Fig. 5C, lanes 1).

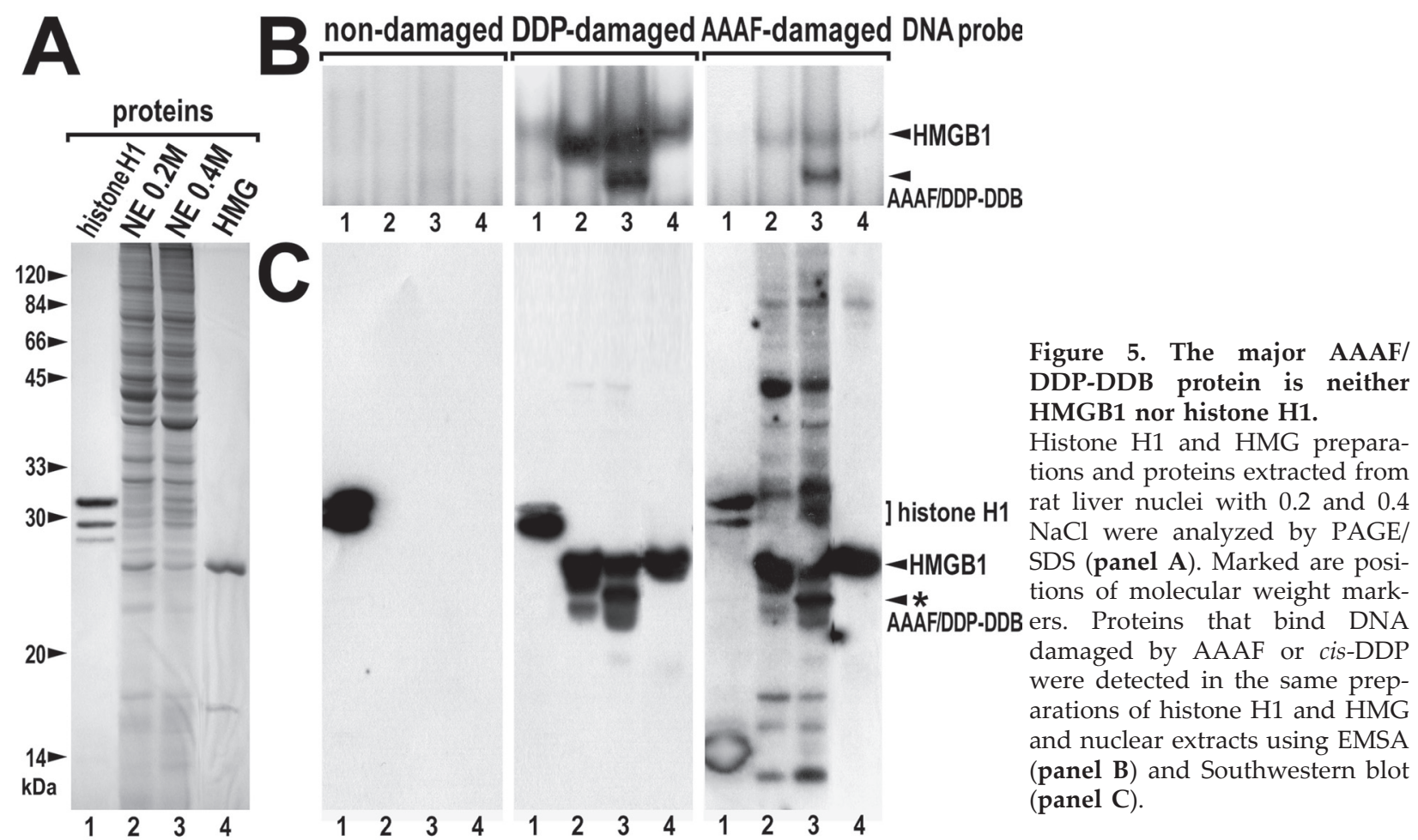


The protein from the HMG preparation that bound damaged DNA had a molecular mass of about 28 kDa (Fig. 5C, lanes 4), and apparently corresponded to HMGB1 (which was further verified by co-electrophoresis with purified HMGB1, not shown). HMGB1 was also detected in nuclear extracts (Fig. 5C, lanes 2 and 3), and apparently formed the lower mobility complex detected in EMSA experiments (Fig. 5B). The major protein band that bound damaged DNA and was detected in the $0.4 \mathrm{M} \mathrm{NaCl}$ nuclear extract (Fig. 5C, lanes 3) but not in the $0.2 \mathrm{M} \mathrm{NaCl}$ nuclear extract, histone $\mathrm{H} 1$ or HMG preparation had an apparent molecular mass of $25 \mathrm{kDa}$ (the protein band marked with asterisk). We propose that this particular protein is our putative AAAF/DDP-DDB protein. Interestingly, this protein was also detected as a minor contaminating band in a histone $\mathrm{H} 1$ preparation purified from chromatin by chromatography on hydroxyapatite (not shown). Because this preparation was eluted from hydroxyapatite-bound chromatin using $0.6 \mathrm{M} \mathrm{NaCl}$ after washing the column with $0.35 \mathrm{M} \mathrm{NaCl}$, this confirmed the strong binding of the putative AAAF/DDP-DDB protein to chromatin.

\section{CONCLUSIONS}

Here we have described and characterized a novel protein that preferentially binds DNA damaged by $\mathrm{N}$-acetoxy-acetylaminofluorene and cis-diamminedichloroplatinum. At present, without a clear identification of the AAAF/DDP-DDB protein, there is no clue about the role of this protein in DNA repair. Although the AAAF/DDP-DDB protein is not ubiquitously expressed it is very abundant in some tissues and its level remains unchanged in cells exposed to specific DNA-damaging agent. This may suggest that the protein is not a key component, if at all, of DNA repair pathways. DNA lesions induced by either AAAF or BPDE are removed by nucleotide excision repair, yet the latter are substrates for preferential repair and are repaired more rapidly in rat liver cells (Rzeszowska \& Widlak, 1999). Here we show that the binding of the AAAF/DDP-DDB protein to the damage induced by BPDE is an order of magnitude weaker as compared to AAAF-damaged DNA. Based on this observation we propose that this protein may compete with repair proteins and shield specific DNA damage making its repair slower and less efficient. Interestingly, the AAAF/ DDP-DDB protein, which is abundant in liver cells of rodents, may be absent in human hepatocellular carcinoma cells. It is well known that although preferential repair of transcriptionally active genes works similarly in rodent and human cells, the overall genome repair is much less efficient in rodents (Bohr, 1987). However, the mechanism of this phenomenon is not clear at the moment. We hypothesize that ex- pression of species-specific DDB proteins that affect the efficiency of damage recognition and removal might contribute to the impairment of global DNA repair in rodents.

\section{Ackowledgements}

This work was supported by the Polish Ministry of Science and Information Society Technologies, grant KBN 3P05A10524.

\section{REFERENCES}

Araujo SJ, Wood RD (1999) Protein complexes in nucleotide excision repair. Mutat Res 435: 23-33.

Banchev T, Srebreva L, Zlatanova J (1991) Purification of histone $\mathrm{H} 10$ and its subfractions under non-denaturing conditions. Biochim Biophys Acta 1073: 230-232.

Birger Y, West KL, Postnikov YV, Lim J-H, Furusawa T, Wagner JP, Laufer CS, Kraemer KH, Bustin M (2003) Chromosomal protein HMGN1 enhances the rate of DNA repair in chromatin. EMBO J 22: 1665-1675.

Bohr VA, Phillips DH, Hanawalt PC (1987) Heterogeneous DNA damage and repair in the mammalian genome. Cancer Res 47: 6426-6436.

Chu G (1994) Cellular responses to cisplatin. The roles of DNA-binding proteins and DNA repair. J Biol Chem 269: 787-790.

de Laat WL, Jaspers NG, Hoeijmakers JH (1999) Molecular mechanism of nucleotide excision repair. Genes Dev 13: 768-785.

Gupta RC (1985) Enhanced sensitivity of ${ }^{32} \mathrm{P}$-postlabeling analysis of aromatic carcinogen:DNA adducts. Cancer Res 45: 5656-5662.

Heflich RH, Neft RE (1994) Genetic toxicity of 2acetylaminofluorene, 2-aminofluorene and some of their metabolites and model metabolites. Mutat Res 318: 73-114.

Kroese ED, van de Poll ML, Mulder GJ, Meerman JH (1988) The role of N-sulfation in the N-hydroxy-2acetylaminofluorene-mediated outgrowth of diethylnitrosamine-initiated hepatocytes to gamma-glutamyltranspeptidase-positive foci in male rat liver. Carcinogenesis 9: 1953-1958.

Łanuszewska J, Widłak P (2000) High mobility group 1 and 2 proteins bind preferentially to DNA that contains bulky adducts induced by benzo(a)pyrene diol epoxide and $\mathrm{N}$-acetoxy-acetylaminofluorene. Cancer Lett 158: 17-25.

McGregor WG, Wei D, Chen RH, Maher VM, McCormick JJ (1997) Relationship between adduct formation, rates of excision repair and the cytotoxic and mutagenic effects of structurally-related polycyclic aromatic carcinogens. Mutat Res 376: 143-152.

Pasheva EA, Pashev IG, Favre A (1998) Preferential binding of high mobility group 1 protein to UV-damaged DNA. Role of the COOH-terminal domain. J Biol Chem 273: 24730-24736.

Petit C, Sancar A (1999) Nucleotide excision repair: from E. coli to man. Biochimie 81: 15-25.

Pietrowska M, Łanuszewska J, Walter Z, Rzeszowska-Wolny J, Widłak P (2000) Detection and characterization of rat protein recognizing DNA damaged by $N$-acetoxyacetylaminofluorene. Cell Mol Biol Lett 5: 423-431. 
Pil PM, Lippard SJ (1992) Specific binding of chromosomal protein HMG1 to DNA damaged by the anticancer drug cisplatin. Science 256: 234-237.

Poirier MC, Fullerton NF, Kinouchi T, Smith BA, Beland FA (1991) Comparison between DNA adduct formation and tumorigenesis in livers and bladders of mice chronically fed 2-acetylaminofluorene. Carcinogenesis 12: 895-900.

Protic M, Levine AS (1993) Detection of DNA damage-recognition proteins using the band-shift assay and southwestern hybridization. Electrophoresis 14: 682-692.

Protic M (1994) Eukaryotic damaged DNA-binding proteins. DNA repair proteins or transcription factors? Ann N Y Acad Sci USA 726: 333-335.

Rzeszowska-Wolny J, Widlak P (1999) Damaged DNA-binding proteins: recognition of $N$-acetoxy-acetylaminofluorene-induced DNA adducts. Acta Biochim Polon 46: 173-180.

Spiker S (1984) High-mobility group chromosomal proteins of wheat. I Biol Chem 259: 12007-12013.

Stein A (1989) Reconstitution of chromatin from purified components. Methods Enzymol 170: 585-603.

Tang MS, Bohr VA, Zhang XS, Pierce J, Hanawalt PC (1989) Quantification of aminofluorene adduct formation and repair in defined DNA sequences in mamma- lian cells using the UVRABC nuclease. J Biol Chem 264: 14455-14462.

Ushay HM, Tullius TD, Lippard SJ (1981) Inhibition of the BamHI cleavage and unwinding of pBR322 deoxyribonucleic acid by the antitumor drug cis-dichlorodiammine-platinum(II). Biochemistry 20: 3744-3748.

Vaisman A, Chaney SG (1995) Induction of UV-damage recognition protein by cisplatin treatment. Biochemistry 34: 105-114

Wang JF, Bashir M, Engelsberg BN, Witmer C, Rozmiarek H, Billings PC (1997) High mobility group proteins 1 and 2 recognize chromium-damaged DNA. Carcinogenesis 18: 371-375.

Widłak P, Rzeszowska-Wolny J (1999) Nuclear matrix and nucleotide excision repair: damage-recognition proteins are not constitutive components of the nuclear matrix. In: Gene Therapy and Molecular Biology; vol. 4, Boulikas T, ed, pp 275-284. Gene Therapy Press, Palo Alto.

Wood RD (1999) DNA damage recognition during nucleotide excision repair in mammalian cells. Biochimie 81: 39-44.

Yaneva J, Leuba SH, van Holde K, Zlatanova J (1997) The major chromatin protein histone $\mathrm{H} 1$ binds preferentially to cis-platinum-damaged DNA. Proc Natl Acad Sci USA 94: 13448-13451. 